\title{
Freely improvised and non-academic electroacoustic music by urban folks
}

\author{
Harold Schellinx \\ ana-R \& IESA \\ Paris, France \\ hars7@mac.com
}

\author{
Emmanuel Ferrand \\ ana-R \& Sorbonne Université \\ Paris, France \\ emmanuel.ferrand@imj-prg.fr
}

\begin{abstract}
We discuss history and characteristics of the evolving global networks of anarchic communities of independent experimental musical artists that over the past half century have continued to flourish outside of established cultural institutions and with but incidental, ad hoc, financial funding. As a case-study related to our own practice we give an in-depth look into the International Headphone Festival Le Placard (1998-2013), a series of ephemeral (headphones only) concert-sites and laboratories for (not only) sound art and electronic music, that was highly innovative and influential also in the worlds of academic and commercial music, though - being the result of collective creative efforts, transmitted in (contemporary equivalents of) the fundamentally aural tradition that is typical of artistic folk modes - this is an influence destined to remain anonymous, hence uncredited.
\end{abstract}

Improvised electroacoustic music, folklore, DIY, circuit-bending, artist networks

\section{INTRODUCTION: URBAN FOLKS}

Attempts at a rigorous and all-embracing definition of TKOMTIUH (an acronym that, with a hat tip to TAFKAP, makes a wink at mid-1990s pop music history, standing as it does for 'The Kind Of Music That Interests Us Here') cannot but fail. The field is large, intricate, entangled and continuously evolving. There are a certain number of (relatively) stable and evidently central musical and performative elements, and there is the role played by the technology. But we should also include the myriads of socialangles as well as the important economical hooks. And a great many of them planes, are they not eagerly twisting and contorting, attempting to turn up their politica/ sides?

It thus almost goes without saying that any succinct circumscription less than a full, detailed, multifaceted, historical and dialectic exposition, will easily be pierced by readily found exceptions; and exceptions to exceptions, and so on.

It is why here we propose historical fiction as an imaginary starting point: for the sake of argument, we postulate that all began at the Scope...

"... a bar out on the way to L.A., near the

Yoyodyne plant. The green neon sign outside ingeniously depicted the face of an oscilloscope tube, over which flowed an ever-changing dance of Lissajous figures. [...] A sudden chorus of whoops and yibbles burst from a kind of juke box at the far end of the room. Everybody quit talking. [...]

"What's happening?" Oedipa whispered. "That's by Stockhausen," the hip graybeard informed her, "the early crowd tends to dig your Radio Cologne sound. Later on we really swing. We're the only bar in the area, you know, has a strictly electronic music policy. Come on around Saturdays, starting midnight we have your Sinewave Session, that's a live get-together, fellas come in just to jam from all over the state, San Jose, Santa Barbara, San Diego ... "

"Live?" Metzger said, "electronic music, live?" "They put it on the tape, here, live, fella. We got a whole back room full of your audio oscillators, gunshot machines, contact mikes, everything man. That's for if you didn't bring your ax, see, but you got the feeling and you want to swing with the rest of the cats, there's always something available." 1

While these Californian folks were having their regular Saturday night live improvised electronic music jams at the Scope, largely unaware, it seems, of the long-time schemed and far grander conspiracies that rule their universe from inside deeply hidden layers, master circuit bender, silicon

\footnotetext{
1 Thomas Pynchon - The Crying of Lot 49 (1966) 
luthier, instrument builder and anti-theoretician-tobe, Qubais Reed Ghazala, then but a 14 year old teenager struggling through junior high, had the epiphanic experience that some forty years later he would colourfully describe in an article called The Folk Music of Chance Electronics, published in the Leonardo Music Journal (Ghazala, 2004).

And then in turn you may imagine the now grown-up anti-theorist Ghazala forging the words and phrases that were to become his Leonardo piece. The clock shows a late hour, the calendar one summer night in 2003. We were in an office room in Belleville in Paris listening to an audio web stream of electronic music (performed at that same time in another, similar office room, studio or factory space over in London, a couple of hundreds of miles away, as part of a Placard event), where one among the somewhat younger, gifted but almost all of them chronically penniless improvising 'noisicians' and brilliant exponents of TKOMTIUH that we had come to know and frequent in the French capital, told us about a plastic bag of his that someone had thrown out with the garbage. And that it had been an act of meanness, that it was done on purpose.

The plastic bag held

the guts of about, like, thirty or forty toys, you know, like some toy samplers, some three or four talking computers. I never recovered from that... It put me behind about... three years, you know. There were the guts of three VTech talking computers, and the guts of like, two Grandstand talking computers. I had like three of like toy samplers, the guts of loads of effect pedals... So I said, 'Is it okay to just leave a bag in your place?' It was just one simple fucking plastic bag... And he was like, 'Yeah, sure'. And I even made a piece of paper saying 'Don't throw away!'...

Every day I think about that... Every day when I'm working, I think: 'Oh yeah, I can use this ...' And then I go: 'Oh no, shit, it was in that bag...' I mean, really. And this guy doesn't know... I wanna kill him! I'm gonna kill him! Anyway, the whole thing was like this bag of circuits. This was, when I first moved to Paris, it was like my way to make money, you know. My work is like, circuit bending, modifying toys, modifying the electronics, and then put it into a new box and sell it. So this is like my kind of, say, my insurance. It was like bringing insurance for like a year, a year of money, in the form of something else, you know... In this case it was like in the form of a plastic bag full or circuit boards and things like that.

And then this guy just threw them away ... ! ${ }^{2}$

\section{DO NOT PLAY EXPERIMENTAL MUSIC}

In an earlier paper in our series of speculative writings on the frontiers, fringes and trenches of contemporary music (Schellinx and Ferrand, 2009) you will find a somewhat unorthodox but in most contexts quite workable definition of the sociomusical activity the roots of which above we traced back to the fictional Scope of the year 1966. Since its -imaginary - launch there, the number of practitioners in the field has been growing steadily, informally (self-)organising within a number of intersecting networks of varying sizes, locally and globally, that together continue to be responsible for the staging of a great many small-scale performances and the production of a vast number of audio recordings, mostly auto-distributed in small editions in divers formats, digital and/or analogue (web, CD, CD-ROM, K7, vinyl). In Schellinx and Ferrand (2009) we think about the music thus practiced as electroacoustic improvisation (EAI) that we define there as "freely improvised music in which at least one among the 'voices' is brought forth by the use of other than a traditional (western or not) (acoustic and/or electrically amplified) musical instrument".

The chaotically sprouting, splitting, expanding, sometimes retracting, networks that consume and produce TKOMTIUH, rhizome-like (mostly outside the reach of mainstream search- and spotlights and largely in what usually is named sub-culture, a 'cultural underground') intersect, to a big, to a small, to a larger, or to a smaller extent, in some instances for the better and sometimes for the worse, with genres identified by one or more among the continuing proliferation (starting in the early 1980s, and accompanied by an exponential increase in quantity, of musical activity and productivity worldwide) of terms, names and labels defined and invented, at times re-defined or re-invented and assigned by musicologists, media theorists, music journalists, critics, et cetera ... to 'musics', that thus ad-hoc are divided into non-exclusive categories like (random sample, listed in no particular musical, technological, ideological or chronological/historical order) industrial music, noise, musique concrète, glitch, free improvisation, art pop, outsider music, post-punk, alternative, ambient, drone, ambient industrial, industrial rock, electronic music, electroacoustic music, phenomenal music, circuit bending, bricolage, musique brut, laptop music, avant pop, plunderphonics, independent, minimal, Nintendocore, field recording ... though there is little doubt that in almost all cases that concern us here, almost everybody will (also) assign the attribute experimental.

\footnotetext{
2 Conversation recorded on cassette tape, July 19/20, 2003
} 
The notion of experimental music, not or at most illdefined from the outset and in the past fifty years by many often merely used as a near-but-not-quite synonym of the nowadays equally vague un-genre of 'avantgarde', came into vogue some seventy years ago, in the 1950s, when the idea, the possibility or maybe even necessity of forms of experimentalism in music at about the same time appeared explicitly, though in very different senses, in the writings of two prominent and outspoken figures of the developments in the new music of their days, Pierre Schaeffer and John Cage.

The first to loud-and-clearly designate certain kinds of musical and sonic activities as 'experimental' was, arguably, Schaeffer, who in the early 1950s presided over the Groupe de Recherches de Musique Concrète de la Radiodiffusion-Télévision Française (GRMC). In 1953, between June 8th and 18th, the Groupe organised the First International Ten Days of Experimental Music (Première Décade Internationale de Musique Expérimentale), in Paris. The music that was being considered, performed and/or discussed on that occasion included the GRMC's and Schaeffer's own musique concrète, (German) electronic music, (American) music for tape and (somewhat curiously) 'exotic music', most likely meaning the incorporation of non-western instruments in the works of western composers (Schaeffer, 1977).

In all of his frenetic, twisted and contorted working and thinking, witnessed by his many writings (all of it in fact sprouting from a single first serendipitous hearing of the closed loop playback of a recorded sound), Schaeffer never ceased to stand in awe of M_usic, with a capital 'M', the further development of which remained a major driving force and the ultimate goal of all his theorizing and practical experimentation.

"Qu'est-ce que la Musique [...] pour un honnête homme du XXe siècle ?" He writes (Schaeffer, 1977): "[I]l faut bien penser qu'un moment viendra où les nouveaux trouvailles, qu'elles soient formelles ou matérielles, et les nouveaux procédés instrumentaux devront rejoindre les fins et les moyens déjà connus et prolonger l'expression musicale la plus universelle. Le contraire serait la négation de toute continuité musicale [...]"

Schaeffer's M_usic is a historical and cultural edifice, a human truth that needs to be prolonged and strengthened, that we need to continue to build. There is something more-than-human about (t)his M_usic. It is not a thing that can be torn down at will by us mortals in order to be re-done. Schaeffer's writings make it clear that he would have very much liked to 'time out' M_usic for a while, long enough to be able to conduct all the studies, experiments and researches he deemed necessary to un-cover the real meaning of all the new technologies and techniques that after the second world war so brutally had invaded its realm. It is in this context that he, with a French sense for melodrama, states (Schaeffer, 1977) that "les manipulations électroacoustiques, capables de transformer radicalement toute structure musicale, c'est posséder la puissance atomique."

In this idea(I) of an 'experimental music' act, we hear and see musician-composers clad in anti-radiation suits, working behind layers of outside protection in order to avoid sonic and/or un-M_usical contamination, carefully proceeding in the step-bystep dissection of alien sonic objects, too afraid, too much in awe, to allow themselves to just believe their (h)ears. ('Fear of Music' is the interesting title of a fine 1979 album by the Talking Heads; though quite unrelated in itself, the title as a - say'diagnosis', we think does provide a worthwhile 'lead' for discussing certain trends in contemporary music). Interestingly, Pierre Henry, Schaeffer's younger partner in crime, early on decided that it was much better to simply jump into musique concrète's newly unveiled ocean of sounds, have all them atomic bombs explode, and then try to learn how to swim so as not to perish. A paradox settled inside musique concrète's creative and ideological core. It gave rise to a deadlock that made continuation of the collaboration between Schaeffer and Henry impossible, and led Henry to pursue his creative and musical visions as an independent researcher/artist, outside official institutions, guided not so much by (attempts at) theory, as by the idea that 'if it sounds good, it can not be bad'; as an antiacademic, rather than as a non-academic. Pierre Henry's freely evolving, un-formal and -in Schaeffer's eyes- un-admissibly anarchic approach to the making of new, 'electronic', musics and sound works, by simply treading the hazy paths that were suggested by one's ears, one's artistic intuition and the available tools, became the obvious 'methodological template' adapted by generations of TKOMTIUH-makers to this very day.

The opposition Schaeffer-Henry is a highly instructive one. It is, in our opinion, a subtle illustration of the differing tension between 'music is a thing that your mind does' and 'music is a thing that \{your body to\} your mind does \{to your body\}', a tension that has continued to seesaw contemporary (experimental) music between opposite poles over much of the second half of the twentieth century.

John Cage's experimental music is of a very different kind, as eloquently worded in the first paragraph of a short article that originally appeared in 1955, later re-printed in his collection of writings Silence (Cage, 1961):

[W]here attention moves towards the observation and audition of many things at once [...] becomes, that is, inclusive rather than exclusive - no question of making, in the sense of forming understandable structures, can arise 
(one is tourist), [...] the word "experimental" is apt, providing it is understood not as descriptive of an act to be later judged in terms of success and failure, but simply as of an act the outcome of which is unknown.

It is the 'experimental' in, roughly, Cage's sense that was hi-jacked by Michael Nyman in his Experimental Music. Cage and Beyond (Nyman, 1999), originally published in 1974, as a term designating the musics that at the time were being practised by a number of kindred (the author almost exclusively discusses) American and British composers/performers, who, strongly influenced by 1960 s pop spirits and the innovative and disrupting avantgarde interventions that were shaking up the fields of the visual and literary arts, jointly took on the role of 'outsider forces', acting on the outskirts of the epoch's musical academia by willingly intersecting and interbreeding with pop music's and visual art's avantgarde (with a particular close affinity with Fluxus). Nyman diametrically opposes this 'experimental music' to the music of the serial avantgarde (including the likes of Karlheinz Stockhausen, Pierre Boulez, lannis Xenakis, Luciano Berio, and so on), "which", he writes, "is conceived and executed along the well-trodden paths of the post-Renaissance tradition" (Nyman, 1999).

(Post-)Cagean experimentalism's radical edges nurtured the original sins from which a musical postmodernism arose whose practitioners, in the guise of -in Georgina Born's (Born, 1995) words"unserious" dissidents of the avantgarde, would continue to be considered less legitimate and less powerful, though in several cases not lesser or even better known than their modernist ('serialist') academic counterparts. The considerable influence of these "unserious" dissidents of the academic musical avantgarde on a new generation of visual artists (many of them non-musicians, but very aware of and with a keen interest in the multimedial creative potential of the then -we speak mid-1960s to mid-1970s - freshly erupted, surging and sounding pop culture) finds an interesting (double) expression in Brian Eno's 'Forward' to (Nyman, 1999). Double, because of the mere fact that it is Eno writing this foreword (a self-acclaimed nonmusician who, as a key-figure in avantgarde and mainstream rock music, played a major role in making unconventional recording techniques and Cagean composition strategies 'mainstream' by introducing them to relatively large pop audiences), and second because of its content. Eno attests to the well-known facts that the emerging 'experimental music' scene found a home not so much within the confines of traditional music venues, as in art colleges, galleries and a host of other 'non-musical' spots. It also warmly welcomed the sonic exploits of non-musicians, whence, be it in a campy sense, also knowingly very bad musical performances by un- or hardly-trained musicians, like the renditions of traditional classical orchestra pieces by the Porthsmouth Sinfonia, were given the status of 'avantgarde music' by the mere will of the presenters and/or hearers (an application of Duchampian 'artification' in the field of music).

At the dawn of a new millennium Eno notes (Nyman, 1999) that what started out as an 'esoteric bubble at the very edge of music' ("the same few dozen people seemed to be at every concert") was transmuted into a mainstream. That however, in our opinion, is a somewhat lopsided view (though this maybe does depend on what precisely one does mean when speaking of 'mainstream'). Though it is undeniably true that the "unserious" musical dissidence of (post-)Cagean experimentalists, together with a Henryean dive into the treasures of the Ali Babaean cave of sounds that opened up along with a fast expanding general consumers market for audio (playback, -recording, -synthesis) technology, since the early-1980s has virally spread to become the chosen artistic mode of expression of a vast group of practitioners, active world-wide, locally, in terms of performances and reach of audience, often Eno's late 1960s observation will continue to hold: at every concert the same few dozen people, a substantial part of whom themselves will be "unserious" musical dissidents.

\section{THEY PLAY URFOIK}

Out in the real world, in our day-to-day practice, it is pretty easy to delineate the psychosociogeographic -artistic, musical- subspace that encompasses the individuals - solo, or more or less loosely organised in groups; part of these will consider themselves as being full- or part-time 'artists' and/or 'musicians', but others will most definitely notthoughts, actions, methods, locations... that together make up the (dynamic, continuously changing both in a geographic and a temporal sense) cultural region that here we will talk about as UFO or URFOlk: URban FOlk music.

When asked, however, as theoreticians to actually define, in understandable phrases, that which is so easy, as if by gesture, to wordlessly discern, we find ourselves being given a task that is near to impossible to complete.

To any element in a set of characteristics designed to comprehensively include all that we would want it to include, there will pop up -and yes, we do repeat ourselves- exceptions, and then exceptions to what one thought was captured by the exception, and so and so further. The multi-dimensional region, as it is, has boundaries that are kind of fractal with respect to attempted 'abstraction'. (So the one way to capture all is to just exhaustively list all of it, and continue to update that list on a regular basis.) 
We saw it all starting at the Scope, from where we can trace its swelling tail, boosted by processes of osmosis through and across categories like high culture $<>$ low culture, musician $<>$ non-musician, player $<>$ listener, determinate $<>$ indeterminate, electronic <> acoustic, composed <> improvised, art $<>$ science..., osmoses with key roles, on the one hand for two clearly demarcated periods of intensive and frantic experimentation in the field of pop music, on the other for ever faster and ongoing further developments in computing, electronics and audio technology.

The first key period, in the second half of the 1960s, saw pop musicians, inspired directly by methods and techniques used for the creation of electronic tape music and musique concrète, and/or profiting from the knowledge and art of the technicians and producers around them, begin to use the recording studio and its sound transforming equipment as instruments and compositional tools. It was also then that pop musicians discovered the aesthetic 'power of destruction', the beauty of noise, of loud and of 'ugly' sounds, the futuristic sonorities of newly invented electronic instruments like Moog's synthesizer, along with the expressive potential of improvisation, as part of an avid exchange and cross-pollination with developments in other musical genres, e.g. 'free jazz' or the free improvisation that in that same period emerged as a named genre somewhere in the mid of a 'nowhere' intersecting the period's avantgarde rock, post-Cagean experimental music, and jazz. (Schellinx and Ferrand, 2009 ; Voorvelt, 1998).

The second key period, that of experimental postpunk pop music, roughly between 1977 and 1983, coincides with a time of severe global economic regression. Central to this second period's rise and development are the fast and substantial increase of the volume of (experimental/alternative pop) musical productions and the number of (full- or part-time) practitioners. Therefore it were not only political motives that increasingly led groups of artists to seek outlets for the products of their creative endeavours outside the, for capitalist cost/profit-ratio reasons, limited opportunities that were provided by the couple of major companies that together over the past twenty years had been controlling most of the global market for the production, distribution and sale of recorded music. It is a period that sees the birth of networks of independent record labels and magazines of varying size and sophistication, that, adopting the utterly independent Do It Yourself (DIY) ethos borrowed from the 'anarcho-nihilistic' punk youth subculture of roughly the same period, that (surtout in words, that is) rejected pretty much anything mainstream and institutional, including 'art' and the need to acquire certain skills (musical and

\footnotetext{
3 Note the curious fact that this once more links our story to Thomas Pynchon's "The Crying of Lot 49", which is all about an
}

other) in order to be able to play musical instruments and produce music. Punk's brute negation of the necessity of 'education' and 'tradition' as a prerequisite for creation became an important source of inspiration for young artists and musicians. (One should note, however, that a surprisingly large number of punk musicians in fact were far more educated and technically accomplished than ide[ologic]ally - they should have been... (:)

In those same years the industry discovered and started to exploit the vast sub-professional market that opened up for audio technology (and that it also helped to create), by producing relatively cheap and easy-to-use 'light' versions of multi-track recording equipment, sound treatment \& effect modules, and an expanding range of sound synthesis and other electronic instruments, most of them aimed at the likewise expanding numbers of aspiring (mainly pop and rock) musicians. The new technology-based musical practices and techniques that until then had been reserved to composers and researchers with access to the capital and highly sophisticated studioequipment owned by broadcast companies and academic or otherwise funded institutions, or to pop and rock musicians with access to commercial recording studios, gradually lost their institutional centre of gravity. Sophisticated audio recording, audio treatment and audio synthesis techniques diverged and spread out (in less or more thinned out and lo-fied versions: in folk versions!) into siderooms, garages, squats, barns, attics, caves, dorms, bedrooms, and into the hands no longer only of trained specialists, but into the hands of whoever felt like using them, into the hands of 'urban folks', of artistic tourists.

Essential to these musical subcultures' ensuing sustained global presence and development were intensive communication and the formation of networks that had a far greater than a merely local or national reach. In its (analogue and pre-internet) early history such communication took place exclusively by means of letters and packages sent through postal services ${ }^{3}$ and through in person travelling, often for collaborations and, usually smallscale, performances. The mails exchanged in many cases took on formats and forms reminiscent and inspired by, in particular, the (Fluxus) mail-art movement that originated in 1960s, which also may be seen as a typical example of a contemporary 'folk(loristic) art' movement. For the publication and distribution of recorded music thankful use was made of the cheap, handy and easy-to-use compact audio cassette tape format that had been available since the mid 1960s (but became especially popular with the advent of 'personal stereo', in the form of the portable cassette player, the "Walkman", introduced by Sony in 1979). The cassette tape enabled artists

ancient and mysterious conflict between mail distribution companies. 
to distribute their original home studio or liverecordings in small, cost effective, handmade editions, that very often took on the form of visual (mail-) art pieces themselves. 'Cassette Culture' remained a core part of URFOlk until in the 1990s a majority of URFOlk community members, following a course subtly imposed by industry, switched from analogue to digital and began publishing and distributing their music on CD-ROM, which, like the cassette tape, could be produced in editions of any desired number. Along with the advent of ever more powerful home computing tools, and the quickly advancing 'total digitalisation' of music and music production, as of the turn of the century web and internet started to provide the major means for communication and for network creation, though communication through postal service and publication of music in small handmade analogue editions, in particular on cassette tape, has continued within URFOlk communities until this very day.

The (hi)story of labels, networks and artists that were and are active in the subculture of independent audio releases is complex and only very partially documented in writing, printed or on websites. Existing documentation often originates from within the community itself, and tends to concentrate on some specific parts reflecting authors' personal taste (see e.g. James, 1992; Sienko and Underwood, 2010; Baily, 2012). Due to its globally scattered nature, built from a great many different subcomponents, it seems near to impossible to even come up with an approximate number for the total of URFOlk productions that were released in small handmade editions on cassette tape and/or CDROM, in, say, the last two decades of the 20th century.

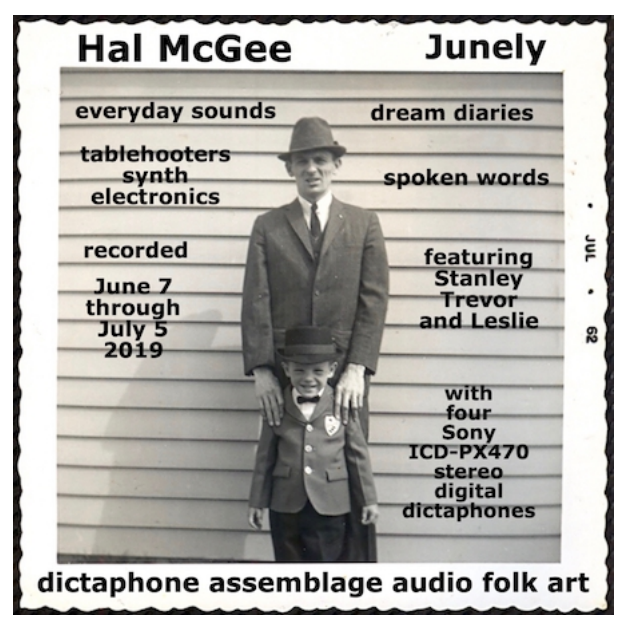

Figure 1: Hal McGee, digital release, July 2019
"I have been using the term 'folk music' to describe what I do since 2011. My audio art since my beginnings in experimental music in 1981 has always reflected on my personal life and experiences. [...] I want to erase the boundaries between my art and my life and to make them one and the same. I am not really interested in art and music that are separate from daily life. [...] My first beginnings as an artist grew out of the Cassette Culture Revolution of the 1980s. The main theme and perhaps lasting value of Cassette Culture is that we emphasized independence of expression, and no compromises in our art-making. [...] We operated outside of and in reaction to the Music Industry. [...] When we listen to a homemade tape we are hearing the artist's life. We feel engaged in the experience because it is real. We understand that we complete the art by actively listening. We become participants in the art instead of passively receiving the sounds like we do in the top-down arrangement of big Music Industry pop stars.

Several years ago somebody asked Don Campau his definition of "folk music" and his reply was: Folk music is whatever the folks are playing. [...] Their music is a part of their everyday lives, and it often reflects on their experiences. [...] We create because we must. It is a necessity of our lives." 4

Our use, above, of the word 'tourist' refers to John Cage's observation made in passing in his description of which will be situations that justify use of the word "experimental". It is apt, indeed, to do so if "one is tourist", he suggests (Cage, 1961).

We think that this 'tourist' image is particularly striking. It gives a useful and appropriate manner to understand the intuitive methodology, not behind all, but behind a very substantial part of the 'free style' URFOlk music as it is being created within the informal DIY networks that have been active and flourishing at least since the early 1980s. A majority of the participants in these networks will be autodidact, with little or no formal musical or technical training. They produce and record their electronic and 'avantgarde' music in what basically is an aural tradition, indeed, a new kind of folk. Often they will have 'travelled' and continue to 'travel' across the full spectrum of contemporary music, like tourists, where they search, then lent and bent, the bits and pieces, the methods and techniques, that interest them, to get at the sounds that they like, irrespective of academic programs, ideologies and aesthetic or formal ideals.

It will be clear that we think of 'tourists' not as blind followers of guides. Our 'tourists' are drifters, and their travels through the world of music are the equivalent of derives in a Situationist sense: "modes

\footnotetext{
${ }^{4} \mathrm{Hal}$ McGee, email to the authors, August 9th 2019
} 
de comportement expérimental liés aux conditions de la société urbaine : techniques de passage hâtif à travers des ambiances variées" (Modes of experimental behaviour linked to the conditions of urban society: techniques of rapid passage through varied ambiances, (Debord, 1958)).

It is another argument for the aptness of using the term 'urban folk' for the only scantily documented, hence barely visible, phenomenon of a (sub-)culture of self-managed, self-funded, self-released music and sound-art that has been thriving for about four decades, along with the folkloristic, autodidact and DIY appropriation and détournement of methods and ideas of post-WWII avantgarde art as its point of departure.

\section{FROM AMSTERDAM TO SOUTH-EAST ASIA TO PARIS}

Music is a performing art. Almost all musicians, as performing artists and (sound) emitters, will (with the -as always - noteworthy exception of a small number of die-hard outsiders) feel a strong need to share their art with (sound) receptors (an audience, whatever its size). Music (making) very much is a social activity and for social acts to thrive one needs space, one needs (a, preferably, variety of) places and the vicinity of people that will want to gather there. Such places and people are most easily found in urban centres, which (partially) accounts for the 'urban' in 'urban folk', for the UR in URFOlk.

Whereas rural areas provide the breathing space and time for retreat and isolation sought by the outsider artist, big cities provide the breeding ground and infra-structure needed for sub-cultural initiatives, sprouting mostly from the informal networks that are formed by the artists themselves and that -in a DIY spirit- are extra-institutional, non-academic, self-managed and operating with no or minimal financial support. The events that they organise will most of the time take place in places that match the available (no-)budget and the type and size of the audience they will attract: small clubs, squats, industrial spaces, artist studio's...

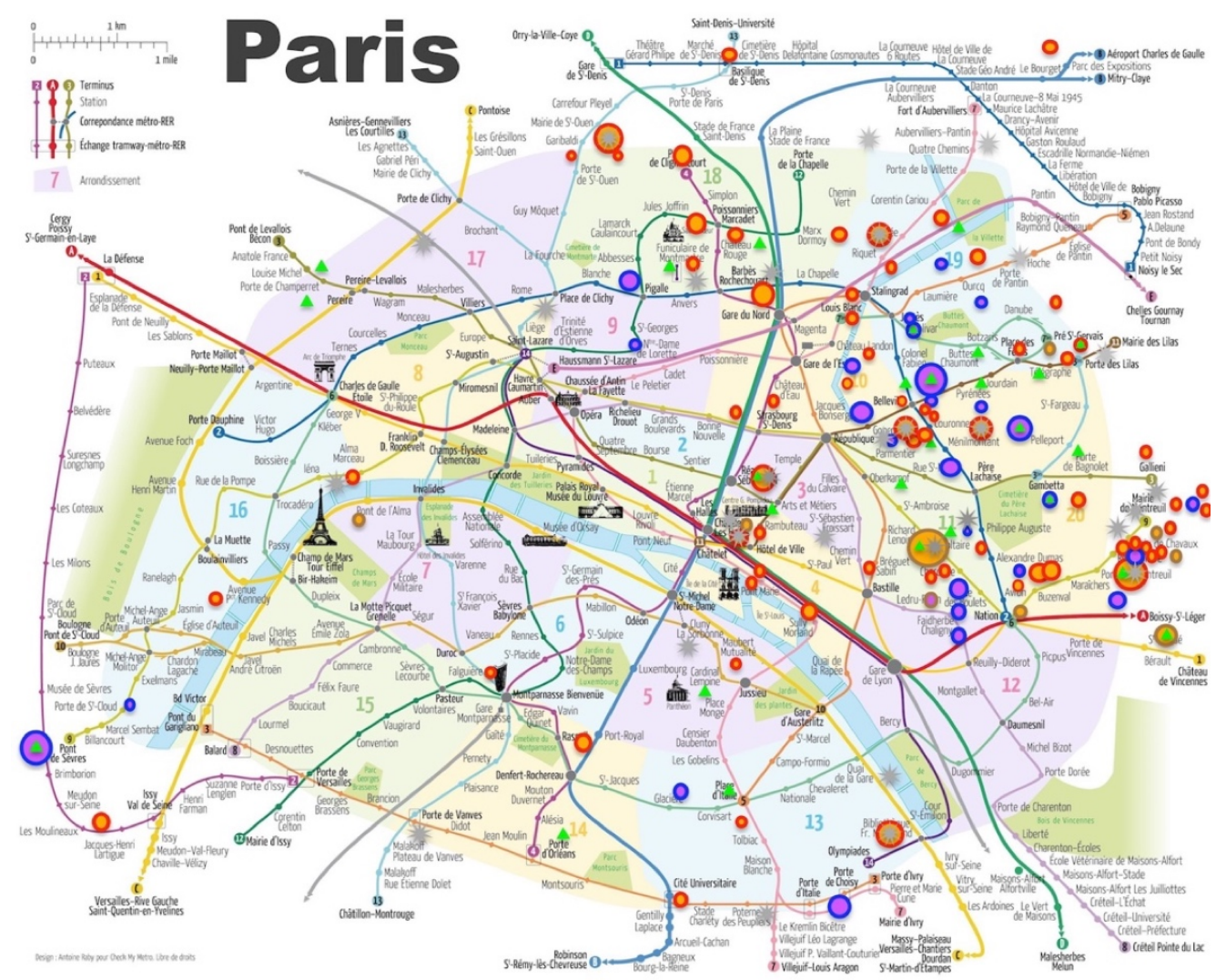

Figure 2: URFOlk locations in Paris, France appr. 2004-2019

Very little systematic study into the history and functioning of these sub-cultural networks of "unserious" musical dissidents and their events seems to be available. Probably this is largely due to a relatively high degree of invisibility to nonparticipants because of the networks' often extreme fringe nature (though, in the authors' opinion, this should on the contrary count as an additional reason to conduct such research). With the exception of some fragments here and there (an example would be the detailed inside-description —in Dutch - of 'Ultra', the experimental post-punk pop subculture in the Netherlands and in particular in Amsterdam, in the period 1978-1983, by one of the authors (Schellinx, 2012)), much seems destined to remain undocumented. Often organisers themselves do not 
keep archives of their activities and existing documentation is spread out over personal collections and archives of participants and visitors.

A noteworthy exception is the independently published study "Not Your World Music (Fermont and della Faille, 2016) that charts the development and the current state of URFOlk music in South-East Asia: Brunei, Cambodia, Indonesia, Laos, Malaysia, Myanmar, Philippines, Singapore, Thailand, Vietnam. The book provides an overview of the labels, networks, places, performers, composers and producers in this region related to what Fermont and della Faille chose to call 'noise music', but which actually covers the full range of URFOlk (they explicitly mention as 'noise subgenres': industrial, minimal ambient, free improvisation, electronic rhythms, sound art et cetera, even reaching out into the fields of academic electronic and contemporary South-East Aaian music). That also in South-East Asia noise and experimental music turn out to be mostly urban phenomena, is but one among the interesting, though maybe hardly surprising, facts that we learn from this work.

Figure 2 shows the distribution of smaller and bigger hubs, of varying importance, for URFOlk events and activities in the city of Paris, frequented by the authors as performers, as audience and/or as organisers over, roughly, the past 15 years.

If you imagine an additional time dimension, the result is a dynamic Parisian URFOlk map, filled with sort of a 'sub-cultural soup' that evolves over time and in which regularly hubs of "unserious" musical dissidence can be seen to come bubbling up here and there. Some will gain in volume (importance) over time; but most after a while either disappear, by bursting into thin air or by gliding into a different spot. Some bubbles indicate the location of bars that on a regular basis provide time and space for lo-profile improvisational and electronic performances, others will be art galleries or more or less spacious artist's studios; some of them are squats, abandoned and derelict buildings, occupied and/or temporarily used by artists; there are a number of smaller and larger spaces rent and run by artists' collectives, a few are or were community spaces, small theatres or studios; and then there are another few spaces run by suburban cultural associations with a special focus on artistic creation...

(It is interesting to note that the majority by far of the URFOlk bubbles on our map are located in the north-eastern part of the city, the "poor part" of Paris.)

The purple coloured bubbles indicate former hubs, that at the time of this writing are no longer active.

\footnotetext{
${ }^{5}$ Cf. http://unpublic.bandcamp.com

${ }^{6}$ A chambre de bonne is a former 'maid's room', usually on the attic floor of a Parisian building. Nowadays, with fewer maids
}

Each of these has its own story. Some of those stories will be of more interest than others. But in general, 'purple' means that this location as an URFOlk space no longer exist. Either literally, because the (derelict) buildings were demolished and replaced by something new. Or because their owner (private or public) put the spaces to a different (often meaning: a more profitable) use. The orange coloured bubbles indicate Parisian URFOlk locations that continue to be accessible and that are currently active. Apart from the orange and the purple coloured circles, a trio of other graphical/color indicators is used to distinguish specific events taking place at the given locations:

_A grey star indicates a location that has hosted one or more events related to the yearly Sonic Protest Festival, an originally Parisian URFOlk initiative that evolved into a European music and sound art festival, which since 2003 has continued to transcend the spectrum of musical genres, auscultating and investigating each of them from within their most demanding and extreme margins. The festival's unity in programming therefore is typically in the requirement of a radicality in artistic approach. Academic electro-acoustic music at Sonic Protest can be found rubbing shoulders with deviant pop music, post-punk noise, sound poetry and musical equivalents of art brut. A hallmark of the Sonic Protest festival is the large space given to artists whose work is truly unclassifiable, like that of André Robillard, a self-taught handyman born in 1931 and a psychiatric hospital intern since the age of 19 , who could be seen performing at the festival's 2017 edition, alongside The Nihilist Spasm Band active in the noise music scene since the 1960s.

_ A green triangle indicates a location that hosted one or more episodes of the International Headphone Festival Le Placard

A brownish coloured contour indicates locations that were host to one or more of our unPublic events. ${ }^{5}$

\section{A BRIEF HISTORY OF LE PLACARD}

What was to become the International Headphone Festival Le Placard kicked off a little more than twenty years ago, in the fall of 1998, in the Belleville neighbourhood in Paris, with 72 hours of musique sans ascenseur ('music without elevator') on the sixth floor of 25 Boulevard de la Villette, in the chambre de bonne ${ }^{6}$ that at the time was home to Erik Minkkinen. 
The following is a brief history of Le Placard as told by Erik Minkkinen, the driving force behind the festival, its main initiator and the one who initially came up with the event's at the time, also socially, highly innovative concepts. ${ }^{7}$

[1] « I did the first Placard in 1998, from September 26 to 29 , in the chambre de bonne where I was living at the time and that had turned into some sort of a studio, a working space where I put up an awful lot of messy electronics. I then had this first idea of starting sort of a bar, or a work shop there. I thought l'd let people come and have them listen through headphones to what I was working on at the moment, meanwhile serving them vodka ... And then thinking that over and over, it turned into this sort of a non-stop 72 hours thing. But it also kept being this work shop thing, starting just with friends. Who wanted to listen had to wait nearby, just around the corner, in a bar called the Zorba. It was almost as if... we had to hand out tickets, there was a queue, a waiting list for those who wanted to climb up to the sixth floor. It was complicated. Sixième étage sans ascenseur (Sixth floor without elevator). And everybody volunteered. The audience volunteered, and all the musicians volunteered. We did that for 72 hours in a stretch. We really had a great time. And at the end of it all, for the next day, we had organised a Tony Conrad concert, at the Garage... »

[2] « We had a lot of contacts with Vienna at the time. That's why I did the second Placard in Vienna, again for 72 hours non-stop, from April 26 to 19 , in 1999. The Vienna Placard was part of another festival there, an electronic music festival called PhonoTaktik, that, unfortunately, no longer exists. Back then, in 1999, it was a festival that took place in a great number of different locations. It was a thing that then was difficult to imagine being possible here in France, like having events pass in buildings that were still under construction, and then, like, on the 30th floor... We were part of the festival's urban route through Vienna, in some apartment. The first Placard worked on the basis of personal invitations, it was a group of friends. In Vienna we started to do the web-streaming thing, with webcams. And installed the idea of a voluntary online inscription: if you wanted to play at the Placard, you reserved your slot with an online form. That was, of course, because we did not really know the Viennese scene, so we needed to get some sort of mouth-to-mouth propagation of what we were doing. And, yeah, there was this gradual accumulation of inscriptions ... we were just trying out, really, but it worked just fine! I actually also learned then in Vienna that it was

kitchenette, shower, toilets) that are not much bigger than a relatively spacious closet. In French a closet is called a placard.

${ }^{7}$ The text is our, often interpretative rather than literal, translation of an interview in French that was part of a 20 minute video compiled by Bastien (family name unknown) from the footage of the 72 hour Parisian Placard that took place early August 2006 in pretty handy to use laptop computers to do live electronics. At the time in Paris we were all still using these bulky desktop office machines. But in Vienna I saw these guys using laptops and I said to myself: "Right, that's the way to go if you want to tour doing electronic music! "»

[3] « In the third edition we started to do streaming sound and images, between cities. We had Brussels, Lisbon... But also we found that it is not all that easy to arrange the virtual participation of such faraway spaces at the precise times that you would like them to join in... »

[4] « For the fourth placard we had two spots in Paris that we could use simultaneously as performing places, so there were a lot more people attending and artists performing than at the third one »

[5] « The fifth placard, in 2002, was a really good one. That year we again had two performing spaces in Paris, but in parallel there was a 72 hours Placard in Tokyo, that we received in Paris as a web-stream. It was like moving from one point in space to another very distant one at will. That was a super interesting experience that made me decide that I would do the future Placards over a stretch of three months, in order to have more liberty in the choice of dates, and have placards happen in many different cities and many different places. On the other hand, it made us lose many of the earlier very special confrontational things, of things happening in different places at the same moment in time. "

In all of its undeniable originality and daring, Minkkinen's Le Placard project was also very much a child of its time. As a paradigm, it could not but have arisen at that precise moment, on the brink of a next century and a new millennium, an until then metaphorical future frontier that suddenly was really crossed, and had us enter an age that, for better or worse, promised total digitalisation and $24 / 7$ global connection.

Large parts of the URFOlk sphere's very foundation is the continuing early adaption and détournement (appropriation, hijacking, diversion, perversion) of emerging technologies for creative purposes. So it is hardly surprising that quite a few members of the then thriving global network(s) of DIY musicians early on began to explore the potential of digital audio compression formats ( $\mathrm{mp} 3$ became available in 1993) in combination with (as of the later 1990s) the exponentially spreading number of faster and faster internet connections and web services, to extend their networks, as a novel means of audio

an artist squat, La Générale, then in Belleville. The video originally appeared on Bastien's public-access.org website, dedicated to his reports on mostly counter-cultural, 'underground', independent art and music events. It also was available on YouTube for a couple of years. Both Bastien's public-access.org website and the YouTube upload of the video, however, were no longer accessible at the time of this writing. 
exchange and for new ways to collaborate. Through online music hosting, distribution and community building services, especially the one provided by the early $\mathrm{mp}$.com ${ }^{8}$ as well as through thematic online bulletin boards, usually called 'groups', hosted by services among which Yahoo! seems to have been the most important one (in the early 2000s).

An example and historically a close relative of $L e$ Placard is the 'Under Deconstruction' group that was initiated late 2000 by French artist Joachim Lapôtre, then based in Paris. The 'Under Deconstruction' bulletin board some months later continued as the Sound Injury group, until in the summer of 2003 a sudden change in Yahoo!'s policy regarding the hosting of the sound files that were at the heart of the Sound Injury group's creative activity, made continuation in that format no longer feasible. (Observe how sudden restrictions on initially free online services that provided artists with near to utopian online freedoms killed many an early $21 \mathrm{st}$ century digital creativity hub.) Starting from an initial sound file posted at the beginning of each month, members of the Sound Injury group (membership was free and open to anyone willing to participate) were invited to use the sound processing tools they had at their disposal to treat that original file in whatever way they liked, and then post the resulting digital sound file back to the group. This gave rise to a second generation of files, that then were treated in similar ways, and so on, until the end of the month, when the group harvested the collections of electronic music tracks of varying length, all derived, in one or more steps, from that month's seed file. The next day the process would start all over again. (Schellinx, 2004)

Each of the many Placard events that took place worldwide made for a temporary, an ephemeral, concert site annex audio laboratory. Pretty much random examples, taken from the authors' personal experiences during the ninth (2006) edition of Le Placard, include a placard in the cellar of the legendary Amsterdam pop concert hall Paradiso, below sold-out performances by Lydia Lunch and Psychic TV that went on above the placard participants' heads; an apartment placard in a Parisian suburb where the participating artists were invited to provide an alternative live soundtrack to the 2006 world champion soccer final match between France and Italy; a placard the central emitting point of which was in a lighthouse on the

\footnotetext{
8 These included audio hosting, audio streaming, 'pay for play', i.e. payback to artists for the visitors' number of listens to their tracks, the on demand pressing of physical CD album pressing, etc... In its heyday, around the turn of the century, mp3.com provided nothing short of a cyber-paradise for independent musicians in any genre, a place to meet, to discover new music and to share experiences with like-minded artists from all over the world. Like many other glimpses of a cyberpunk utopia given by these early web days, also this proved to be but a bubble and it soon came to burst, for —we will now say: 'obviously'- mp3.com
}

island of Ameland, to the north of the Netherlands, with contributions from a great many spots in the world; et cetera. Not in the least thanks to the internet and its tools placards make fine examples of what in situationists' terms is named 'constructed situation' (situation construite): a moment of life concretely and deliberately constructed by the collective organisation of a unitary ambiance and a game of events (moment de la vie, concrètement et délibérément construit par l'organisation collective d'une ambiance unitaire et d'un jeu d'événements, (Debord, 1958)): one of the essential ingredients in the construction of these specific situations was the collective self-management of the Placard's program by the artists, who were given an online form that enabled one to reserve 30 minute slots in which to perform, on a 'first-come-first-served' basis. The live audio web stream was another such ingredient. Most Placards would welcome performances from whoever wanted to contribute from wherever on the globe, while the audio web stream also enabled the setting up of 'listen-only' spots. Thus each Placard event-laboratory would ideally function as a root from which a network of related ephemeral concert sites/laboratories could sprout. The link to the web stream, by the way, in general would not be announced publicly. It was only communicated to those that at the time of the event were willing to use IRC (Internet Relay Chat) to receive information and discuss the music and all that was related, once more stressing the fundamentally social character of the 'Placard situation'. This ongoing IRC chat usually was projected at the Placard's locations, for all to follow and read.

During a number of the Placards in the late 2000s, Jan Zimmermann would join the event with his live vinyl cutting machine, recording large parts of the performances directly onto one-copy-only gramophone records. That first time that happened was in 2006, at the 72 hours Placard at the Belleville La Générale.

« I met Jan before at other festivals, " Erik Minkinnen told, " and, yeah, his *free* live vinyl cutting work resonates beautifully with the *free* performing of the musicians that together make a Placard. And the other great parallel is the idea of 'unique copies', of there only being *one* of something. You know ... the concerts... there's hardly anything like an archive, there are no

was committing commercial suicide, and their quite amazing set of services was economically completely unsustainable. It is interesting to compare this to Bandcamp, currently the arguably most effective online hosting and distribution service for independent musicians, which does provide visitors similar possibilities to discover new artists and new music, but which functions on a strictly 'down to earth' (and economically sustainable) basis, where selling of tracks and albums to interested listeners (fans) is the primary goal, and lacking tools that would encourage communication and community building between artists. 
archives of the Placard, because... » The video shows Erik thinking deeply about how to phrase this ... « It is not that I'm categorically opposed to, say, 'archives' of the Placard... but what comes to be in a Placard concert, for the time of its duration is a very intimate relationship between the artist and the person who listens - maybe physically very close, at mere centimetres distance, or physically very far, at the other side of the globe... but through headphones this always will feel but a touching's apart- that's an intimacy that the artist and the public share, in pairs... It is something that you may talk about, that you may try to put into words... But at heart it will always remain something unique to that pair... So... Listening to a Placard concert is very much like cutting your own private vinyl... »

\section{LE PLACARD, QUESTIONS OF RESEARCH AND TRANSMISSION}

Apart from their intrinsic artistic interest, the many editions of Le Placard (especially in the period ranging from 1998 to, roughly, 2013), gathering together a variegated international group of artists, took on the role of a kind of informal and selforganised colloquium at an European or even global level, frequented by practitioners and experimenters of improvised electronic music. It brought to the fore what we can best interpret as a broad research effort with a real collective dimension (albeit a noncentralized one) that at times gave rise to genuine phenomena of emergence, that is, distributed innovation. There are few technical practices that we can associate with this or that individual creator. Indeed, going beyond individual experiments on traditional techniques such as the design of electronic circuits or software development (we imagine geeks reclusive in their cellars), the informal, anarchic, Placard community was able to construct truly effective instances of knowledge transfer.

This is relatively obvious since the ubiquitous generalization of global interconnection provided by the internet and web tools, but we can also point at several earlier instances, like the 'Experimental Musical Instruments' magazine, published and edited by Bart Hopkins from 1985 to 1999 , and to which, for example, also Qubais Reed Ghazala was a regular contributor. Above we already mentioned the role played by mailing lists in communication and collaboration between artists in the early days of the web. A list like 'Analogue Heaven', where the earliest online messages date back to 1993, way into the early 2000 s continued to contribute a lot to the dissemination of the very elaborate but largely non-academic technical knowledge of analogue electronic circuitry used for sound production. It is also here that we first come across the free software community, whose decentralized organization corresponds well to the ideas of emerging innovation that are implicitly at work in contexts where, due to artistic practices that generate but infinitesimally small financial stakes, claims of intellectual property are but rarely put forward. This lack of relevant financial stakes may also be the reason why the artists' ego's here seem to be far less exacerbated than they are elsewhere, as evidenced by the anonymity and/or the (ab)use of ranges of (more or less obscene) pseudonyms that are generally used by the artists for their inscription at Placard events.

The early years of Le Placard coincided with the apogee of a very austere manner of performing electronic music, which today, in its pure form is but little practiced anymore: the artist presenting herself alone, facing the audience armed but with a single computer running patches of software like Pure Data, and where the musician's (inter)activity was limited to the brief caresses with his fingers of the machine's touchpad. (Nowadays many artists appear to have learned how to add action ('counterfeit aura', cf. (Cascone, 2002)) to their laptop performance, but how sincere this really is...?) it remains of special interest to consider that particular period (the early 2000s) from the point of view of transmission of knowledge and techniques. As step-by-step advances in the mastering of the used software in these non-academic circles occurs not via the technical and scholarly comprehension of the mathematical processes underlying signal processing, but almost exclusively through an empirical analysis of concrete patches and the gradual evolution of techniques copied from others (hence effectively constituting a 'folklore'), one could observe how, from year to year, a sound with truly collective characteristics evolved, with the same innovations declined by many different stakeholders. Moments of collective listening as those provided by Le Placard included a great many moments of exchange, and the festival's success is surely more than partly due to this so very useful community function.

It may be that this prosperous past period of nonacademic technical creativity has come to (a temporary?) end, rendered marginal by the general availability of powerful software tools like 'Ableton Live', a software that - we should not forget- was originally inspired by the trackers used by the producers of an often pretty 'experimental' techno music and that managed to become a standard thanks to its accessible ergonomics and the possibility to incorporate, via the 'plugin' concept, much of what already existed in more disparate forms and formats in the underground URFOlk community. It, remarkably, also follows that one regularly recognizes in today's commercial music productions what are the evident by-products of some of the 'experimental hacks' that surfaced and circulated already 10 or more years ago in underground electronic music scenes. 


\section{THE FUTURE ALWAYS WAS YESTERDAY}

In his contribution "Necessity and Choice in Musical Forms: Concerning musical and technical means and political needs" to (James, 1992), Chris Cutler gives the following four characteristics of the 'Folk Mode' of human music making (which he considers in dialectical opposition with the eye (notation) based bourgeois 'Art Mode'):

the medium of folk mode musical generation and perpetuation is based in human memory, it centres around the ear;

_ the practice of folk mode music is an expressive attribute of a whole community;

there are no finished or definitive pieces of folk mode music, and, though there is individual contribution, there is no element of personal property;

there is no productive distinction between the roles of composer and performer, the generation and production of folk mode is a socially seamless and single process in which improvisation plays a central part.

One readily verifies that Cutler's four characteristics coincide with the defining properties, as outlined in the above, of the working modes and the (intuitive) methodology of large sections of contemporary networks of independent artists active in the fields of free improvisation and non-academic, extrainstitutional electroacoustic music.

They play urban folk. It's URFOlk.

"We need and want to "promote" an art without any identity, without even the identity of art. An art that is no longer given as art, whatever its legitimating authority, and that so will manage to greatly increase its performative potential. An art therefore without spectators, an art without public. And, at the same time, an art that is not claimed by its author[s], able to intervene (performatively) with more efficiency in \& on reality than through that which one labels as 'art', always suspect of pretence. ${ }^{9}$

\section{REFERENCES}

Bailey, T. (2012) Unofficial Release. Self-released and handmade audio in post-industrial society. Belsona Books
Born, G. (1995) Rationalizing Culture. IRCAM, Boulez and the Institutionalization of the Musical Avant-Garde. University of California Press.

Cage, J. (1961) Silence. Lectures \& Writings. Marion Boyars, London.

Cascone, K. (2002) Laptop Music: Counterfeiting Aura in the Age of Infinite Reproduction. Parachute, 107.

Fermont, C. and della Faille, D. (2016) Not your world music: Noise in South East Asia, politics, identity, gender and global capitalism. Syrphe/Hushush.

Debord, G. (ed) (1958) Internationale Situationniste, Numéro 1, Paris.

Ghazala, Q.R. (2004) The Folk Music of Chance Electronics: Circuit-Bending the Modern Coconut. Leonardo Music Journal, 14.

James, R. (ed) (1992) Cassette Mythos. Autonomedia, New York.

Moineau, J-C. (2012) L'art où l'on ne l'attend pas ? http://j.mp/unpublicmoineau (retrieved: December 7 2019)

Nyman, M. (1999) Experimental Music. Cage and Beyond. Second Edition. Cambridge University Press.

Schaeffer, P. (1977) De la musique concrète à la musique même. La Revue Musicale (303-305), Paris.

Schellinx, H. (2004) Pure sound injury. http://soundinjury.soundblog.net (retrieved: December 7 2019)

Schellinx, H. (2012) Ultra. Opkomst en ondergang van de Ultramodernen, een unieke Nederlandse muziekstroming (1978-1983). Lebowski Publishers, Amsterdam.

Schellinx H. and Ferrand, E. (2009) Az elektroakusztikus improvizáció mint metanyelv és rögzített pont (Electroacoustic improvisation as metalanguage and fixed point (i)). In Batta, B. (ed), Médium Hang Esztétika - Zeneiség a mediális technológiák korában. University of Szeged, Szeged.

Sienko, C. and Underwood, S. (eds). (2010) As Loud as Possible. Noise Culture Magazine. Issue 1.

Voorvelt, M. (1998) British Post-Punk Experimental Pop (1977-1983). PhD Thesis, University of Leeds.

\footnotetext{
${ }^{9}$ Freely adapted from Moineau, 2012
} 